Open Access

\title{
Distribution and Antifungal Activity of Endophytic Fungi in Different Growth Stages of Chili Pepper (Capsicum annuum L.) in Korea
}

\author{
Narayan Chandra Paul, Jian Xin Deng, Hyun Kyu Sang, Young Phil Choi and Seung Hun Yu* \\ Department of Agricultural Biology, Chungnam National University, Daejeon 305-764, Korea \\ (Received on July 5, 2011; Revised on December 7, 2011; Accepted on December 12, 2011)
}

This study investigated the distribution of endophytic fungi obtained from the surface sterilized tissues of leaves, stems and roots of chili pepper (Capsicum annuum L.) plants in seedling, flowering and fruiting stages in Korea and their antifungal activity. A total of 481 isolates were recovered and were identified using molecular techniques. Based on rDNA ITS gene sequence and phylogenetic analysis, 21 fungal genera were characterized, belonging to 16 Ascomycota and 5 Basidiomycota. Penicillium in seedling stage, Fusarium in flowering stage, Colletotrichum followed by Fusarium, Alternaria and Xylaria in fruiting stage was predominant and Alternaria, Cladosporium and Fusarium were common in all growth stages. Among 481 endophytes 90 phenotypes were evaluated for the antimicrobial activity against three major pathogens (Phytophthora capsici, Colletotrichum acutatum and Fusarium oxysporum) of chili pepper. Among them 16 isolates inhibited the growth of at least one test microorganisms. Three strains showed a broad spectrum antifungal activity and displayed strong inhibition against chili pepper pathogenic fungi.

Keywords : endophytic fungi, Capsicum annuum L., molecular taxonomy, antifungal activity

Endophytes are microorganisms that reside within internal tissues of living plants without visibly harming the host plant (Fisher and Petrini, 1987). Endophytic microorganism have been found in all plant families (Sieber et al., 1988), which represent many species in different climate regions of the world (Bussaban et al., 2001; Fisher et al., 1992; Larran et al., 2001, 2002; Paul et al., 2007; Petrini and Carroll, 1981; Spurr and Welty, 1975). Endophytic attention has increased in recent years because of its taxonomic diversity (Chen et al., 2011a), its multiple functions including potential use as genetic vectors (Murray et al., 1992); host plant growth promotion and fitness (Baltruschat et al.,

\footnotetext{
*Corresponding author.

Phone) +82-42-821-5762, FAX) +82-42-823-8679

E-mail)shunyu@cnu.ac.kr
}

2008; Tanaka et al., 2006; Tudzynski and Sharon, 2002). Furthermore, they are the source of secondary metabolites (Fisher et al., 1986; Paul et al., 2007; Strobel et al., 1996) and biological control agents (Bacon, 1990; Clay, 1989; Dorworth and Callan, 1996; Schardl et al., 1991). Carroll (1988) has demonstrated the enhancing of the host survival against fungal pathogens in some plant-endophyte associations.

Chili peppers that belong to the genus Capsicum are probably the most widely consumed spice in the world (Rozin and Schiller, 1980). Capsicum annuum L. is one of the five most economically notable species of chili pepper (Linda perry et al., 2007). Cultivated crop plants may live in association with a variety of mycoflora. However, endophytic fungi in chili pepper plants have not been studied yet. For that reason, the investigation of endophytic fungi associated with Capsicum annuum L. from seedling stage to fruiting stage is carried out.

The objective of this study was to investigate the presence, distribution, diversity and antifungal activity of endophytic fungi in seedling, flowering and fruiting stages of chili pepper (Capsicum annuum L.) in Korea.

\section{Materials and Methods}

Host species and sampling. Chili pepper plants (Capsicum annuum L.) were selected for the study as this plant is growing all over Korea and common in all other countries in the world. Sampling sites of this study were Daejeon farmer's field, Chungnam province, middle of Republic of Korea and Plants were selected in seedling, flowering and fruiting stages of chili pepper growth stage. In our study, the seedling stage means the early stage of chili pepper growth i.e, 10 days of seedling transplanting when 5-7 leaf comes, the flowering stage means the growth stage when flowers started to come i.e, after 25 days of planting and fruiting stage means when chili pepper fruits started to come i.e, after 40 days of planting. Fifteen plants of each growth stage were selected and leaf, stem and root samples from each plant were randomly excised and brought to the laboratory in separate sterile polyethylene bags. 
Isolation of endophytic fungi. Samples were cleaned under running tap water to remove debris and then air dried and processed within $5 \mathrm{hrs}$ of collection. From each sample, 10 segments of $1 \mathrm{~cm}$ length were separated and treated as replicates. Tissue segments were surface sterilized by immersing in $95 \%$ ethanol for $1 \mathrm{~min}$, sodium hypochlorite (4\% available chlorine) for $4 \mathrm{~min}$ and $95 \%$ ethanol for $30 \mathrm{~s}$ and then the surface sterilized samples were washed in sterile water three times to remove the surface sterilization agents. Samples were allowed to dry on paper towel in a laminar air flow chamber. Ten segments were placed horizontally on separate Petri dishes containing potato dextrose agar (PDA) and rose bengal chloramphenicol agar (DRBC) supplemented with the antibiotic streptomycin sulfate $0.4 \mathrm{mg} / \mathrm{mL}$ to stop bacterial growth. After incubation at $25^{\circ} \mathrm{C}$ for 5,10 and 25 days, individual hyphal tips of the developing fungal colonies were collected and placed onto PDA media and incubated for 5-10 days and checked for culture purity. Eventually pure cultures were transferred to PDA slant tubes and 20\% glycerol stock solution. Strain number were assigned for selected isolates and deposited to the Fungal Herbarium of the Chungnam National University, Daejeon, Republic of Korea.

Genomic DNA extraction, PCR amplification and sequencing. For the determination of ITS region of rDNA, genomic DNA was extracted from 90 pure culture isolates using the method of Park et al. (2005). Primers ITS1 (5'TCCGTAGGTGAACCTGCGG-3') and ITS4 (5'-TCCTCC GCTTATTGATAT GC-3') were used for the amplification of the fungal rDNA internal transcribed spacers (ITS) regions of all isolates. PCR amplification was carried out (White et al., 1990) in i-cycler (BIO-RAD, USA) for 30 cycles of $94^{\circ} \mathrm{C}$ for 1 min denaturing, $55^{\circ} \mathrm{C}$ for $1 \mathrm{~min}$ annealing and $72^{\circ} \mathrm{C}$ for $1.30 \mathrm{~min}$ extension. Initial denaturing at $94^{\circ} \mathrm{C}$ was extended to $5 \mathrm{~min}$ and the final extension was for $10 \mathrm{~min}$ at $72^{\circ} \mathrm{C}$. The PCR product was purified using Wizard PCR prep. kit (Promega, Madison, WI, USA). Purified double stranded PCR fragments were directly sequenced with BigDye terminator cycle sequencing kits (Applied Bipsystems, Forster City, CA, USA) by following the manufacturer instructions. The gel electrophoresis and data collection were performed on an ABI prism 310 Genetic Analyser (Applied Biosystems, Forster City, CA, USA).

Phylogenetic analysis. The rDNA ITS gene sequences were compared by BLAST search with the sequences available in the GenBank database. Sequences generated from materials in this study and retrieved from GenBank were initially aligned using the program CLUSTAL X (Thompson et al., 1997), and then the alignment was refined manually using the PHYDIT program version 3.2 (Chun, 1995; available at http://plaza.snu.ac.kr/jchun/phydit). A neighbor-joining tree was constructed with Kimura's 2parameter distance model (Kimura, 1980) using the PHYLIP 3.57c package (Felsenstein, 1985). The bootstrap analysis using 1000 replications were performed to assess the relative stability of the branches.

Fungal diversity. Isolation rate (IR), isolation frequency (IF) and relative frequency (RF) was calculated by the following formula:

Isolation rate $(\%)$

$$
=\frac{\text { Total no. of isolates from tissues or growth stages }}{\text { Total }}
$$

Total no. of endophytic isolates obtained

Isolation frequency

$$
=\frac{\text { Total no. of isolates from tissues or growth stages }}{\text { Total no. of segment incubated }}
$$

$$
\begin{aligned}
& \text { Relative frequency (\%) } \\
& =\frac{\text { Total no. of isolates from a single taxa }}{\text { Total no. of taxa obtained from all tissues }}
\end{aligned}
$$

Fungal dominance was determined by Camargo's index (1/ $S$ ), where $\mathrm{S}$ represents species richness. A species is defined as dominant if $\mathrm{P} i>1 / S$ (Camargo, 1992), where $\mathrm{P} i$ is the relative abundance of a species $i$, defined as the number of competing species present in the community. The Simpson (Simpson, 1949) and Shannon (Shannon and Weaver, 1949) diversity indices were calculated in each growth stage and the total population.

Screening for antifungal activity. Endophytic fungi were screened by dual culture method for antifungal activity against potentially pathogenic fungi of chili pepper, Phytophthora capsici, Colletotrichum acutatum and Fusarium oxysporum. The phytopathogenic fungi were collected from the culture stock of Plant Pathology Laboratory, Chungnam National University, Daejeon, Republic of Korea. Five-dayold disks (5 $\mathrm{mm}$ diameter) of endophytes were placed on 3 points of Petri plates containing PDA medium. Test pathogens were inoculated at the center of PDA plates. Plates were incubated at $25^{\circ} \mathrm{C}$ for 5-8 days. Antifungal activity was assessed by the size (diameter in $\mathrm{mm}$ ) of the inhibition zones. Each experiment was repeated three times.

\section{Results}

A total of 481 fungal endophytes were obtained from 900 tissue segments (equal number of tissue segment plated in every growth stages of chili pepper to observe the proper distribution of endophytic fungi) in three different growth 

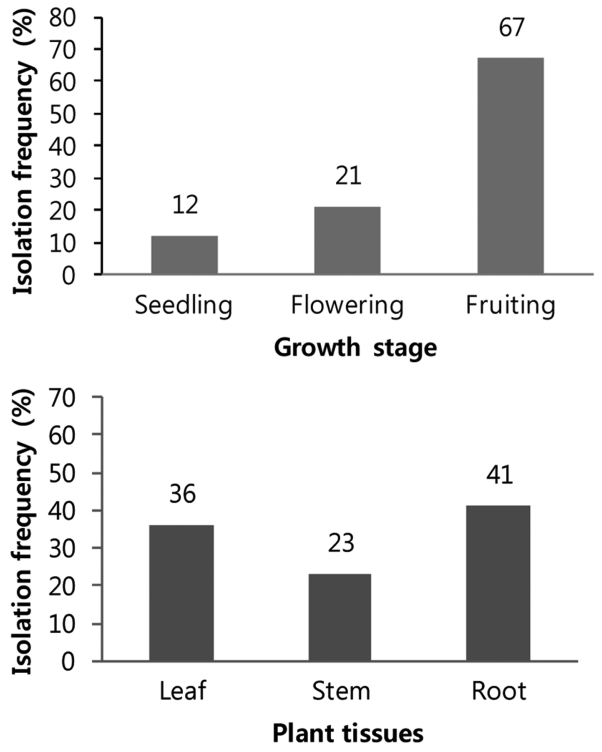

Fig. 1. Isolation frequency (\%) of endophytic fungi obtained from chili pepper. Abundances of endophytes compared with healthy tissue segments incubated (leaf, stem and roots) is shown in seedling, flowering and fruiting stages of chili pepper plant.

stages of chili pepper with general isolation rate of 0.53 . However, the IF and IR in three growth stages of chili pepper (Seedling, flowering and fruiting) were 12\%, 21\% \& $67 \%$ (Fig. 1) and 0.19, $0.34 \& 1.08$ (Table 1), respectively. All endophytic isolates were grouped into 90 phenotype groups (including both identified genera and morphologically distinct but unidentified types). Many isolates did not produce conidia or spore. So, endophytic fungi recovered from Capsicum annuиm L. were identified by the sequence analysis of ITS region of rDNA gene. Thirty three distinctive fungal genotypes were detected at a $>90 \%$ sequence similarity threshold (Table 2 ) representing 28 Ascomycota phyla, 5 was Basidiomycota and 14 endophytic taxa which were unidentified or unknown fungi (Table 3; Fig. 2).

There were differences in the isolation frequencies from various plant organs also. Forty one percent of isolates were originated from root tissues, whereas $36 \%$ of the isolates were from leaf samples and $23 \%$ were from stem tissues (Fig. 1). Each plant hosted several fungi. The distribution of isolates among 90 endophytic fungi approximated a long normal pattern, with many common taxa and many rare taxa. The genera of the fungi isolated from chili pepper were Alternaria, Aspergillus, Bionectria, Chaetomium, Cladosporium, Colletotrichum, Cordyceps, Fusarium, Geomyces, Gnomonia, Heterobadisidion, Irpex, Paecilomyces, Papulaspora, Penecillium, Peyronellaea, Phanerochaete, Phialophora, Phlebiospsis, Plectosphaerella and Xylaria. Dominant species with high RF value were Colletotrichum sp. $(18.92 \%)$ and Fusarium sp. (18.71\%) which were isolated frequently in fruiting stage. In seedling stage Penicillium (6.24\%) species was dominated. Alternaria sp. (7.48\%) and Cladosporium sp. (3.96\%) were common in seedling, flowering and fruiting stage. The RF value of Xylaria sp. and Heterobasidion sp. were $3.53 \%$ and $1.87 \%$, respectively.

Diversity of endophytic fungi. To characterize the diversity, we calculated Camargo's index, Simpson's diversity index and Shannon diversity index. The values obtained by these analyses indicate that the diversity of fungal endophytes is very high. The species richness for all tissues and growth stages was 34 (19, 16 and 15 in seedling, flowering and fruiting stage, respectively. Unknown isolates were counted as single species). Diversity indices in different growth stages of Capsicum annuum L. in Korea are listed in Table 2. Camargo's richness $(1 / S)$ showed higher species diversity in seedling stage $(1 / S=0.052)$ over flowering $(1 / S=0.062)$ and fruiting stage $(1 / S=0.066)$. The overall $1 / S$ was 0.029 which shows the high species diversity. The Simpson and Shannon diversity indices were higher in seedling stage $(1-D=0.837$ and 2.349). In flowering and fruiting stages the indices were $0.0677,1.746$ and $0.773,1.739$, respectively. The overall diversity of endophytic fungal isolates was $1-D=0.800$ and 2.068 (Table 2).

Antifungal activity. Dual cultures of fungal endophytes isolated from Capsicum annuum L. are shown in Table 4.

Table 1. Endophytic fungi isolated from leaf, stem and root tissues of Capsicum annuum L. in seedling, flowering and fruiting stages

\begin{tabular}{|c|c|c|c|c|c|c|c|c|c|}
\hline \multirow{2}{*}{ Growth stage } & \multicolumn{4}{|c|}{ Segment plated } & \multicolumn{3}{|c|}{ Isolates recovered } & \multirow{2}{*}{ Total } & \multirow{2}{*}{$\mathrm{IR}^{\mathrm{a}}$} \\
\hline & Leaf & Stem & Root & Total & Leaf & Stem & Root & & \\
\hline Seedling & 100 & 100 & 100 & 300 & 33 & 8 & 16 & 57 & 0.19 \\
\hline Flowering & 100 & 100 & 100 & 300 & 46 & 14 & 41 & 101 & 0.34 \\
\hline Fruiting & 100 & 100 & 100 & 300 & 94 & 90 & 139 & 323 & 1.08 \\
\hline Total & 300 & 300 & 300 & 900 & 173 & 112 & 196 & 481 & 0.53 \\
\hline $\mathrm{IR}^{\mathrm{a}}$ & & & & & 0.56 & 0.37 & 0.65 & 0.53 & \\
\hline
\end{tabular}

${ }^{a}$ Means isolation rate estimated in percentage (\%) 
Table 2. Fungal endophytes isolated in different growth stages of Capsicum annuum L. and fungal diversity indexes

\begin{tabular}{|c|c|c|c|c|c|c|}
\hline \multirow{2}{*}{ Genera } & \multirow{2}{*}{ Fungal taxa } & \multicolumn{3}{|c|}{ Fungi in growth stage } & \multirow{2}{*}{ Total } & \multirow{2}{*}{$\operatorname{IF}^{\mathrm{a}}(\%)$} \\
\hline & & Seedling & Flowering & Fruiting & & \\
\hline Alternaria & A. alternata & 3 & 6 & 27 & 36 & 7.48 \\
\hline \multirow[t]{2}{*}{ Aspergillus } & A. tubingensis & & 2 & & 2 & 0.83 \\
\hline & A. versicolor & 2 & & & 2 & \\
\hline Bionectria & B. ochroleuca & & & 1 & 1 & 0.21 \\
\hline Chaetomium & Chaetomium sp. & & 1 & & 1 & 0.21 \\
\hline \multirow[t]{4}{*}{ Cladosporium } & C. colombiae & 1 & & & 1 & 3.96 \\
\hline & C. gossypiicola & 3 & 2 & & 5 & \\
\hline & C. oxysporum & & & 1 & 1 & \\
\hline & Cladosporium sp. & 2 & 5 & 5 & 12 & \\
\hline \multirow[t]{2}{*}{ Colletotrichum } & C. acutatum & 3 & 4 & 81 & 88 & 18.92 \\
\hline & C. gloeosporioides & 2 & 1 & & 3 & \\
\hline Cordyceps & C. nutans & & 1 & & 1 & 0.21 \\
\hline \multirow[t]{2}{*}{ Fusarium } & F. oxysporum & 4 & 15 & 69 & 88 & 18.71 \\
\hline & F. solani & 1 & & 1 & 2 & \\
\hline Geomyces & G. pannorum & 1 & & & 1 & 0.21 \\
\hline Gnomonia & G. setacea & & & 1 & 1 & 0.21 \\
\hline Heterobadisidion & Heterobasidion sp. & & & 9 & 9 & 1.87 \\
\hline Irpex & I. lacteus & & 2 & & 2 & 0.42 \\
\hline Paecilomyces & P. inflatus & 1 & & & 1 & 0.21 \\
\hline Papulaspora & Papulaspora sp. & & & 1 & 1 & 0.21 \\
\hline \multirow[t]{6}{*}{ Penecillium } & P. citrinum & 1 & & & 1 & 6.24 \\
\hline & P. crustosum & 1 & & & 1 & \\
\hline & P. expansum & 1 & & & 1 & \\
\hline & P. olsonii & & 1 & & 1 & \\
\hline & P. oxalicum & 1 & & & 1 & \\
\hline & Penicillium sp. & 20 & 2 & 3 & 25 & \\
\hline Peyronellaea & P. glomerata & & & 2 & 2 & 0.42 \\
\hline Phanerochaete & P. sordida & & 2 & & 2 & 0.42 \\
\hline Phialophora & P. cyclaminis & & 1 & & 1 & 0.21 \\
\hline Phlebiospsis & P. gigantea & & & 1 & 1 & 0.21 \\
\hline \multirow[t]{2}{*}{ Plectosphaerella } & P. cucumerina & 1 & & & 1 & 0.42 \\
\hline & Plectosphaerella sp. & 1 & & & 1 & \\
\hline Xylaria & Xylaria sp. & & 2 & 15 & 17 & 3.53 \\
\hline \multicolumn{2}{|c|}{ Unidentified } & 8 & 54 & 106 & 168 & 34.93 \\
\hline \multicolumn{2}{|c|}{ Total no. of fungal isolates } & 57 & 101 & 323 & 481 & \\
\hline \multicolumn{2}{|c|}{ Species richness $(S)$} & 19 & 16 & 15 & 34 & \\
\hline \multicolumn{2}{|c|}{ Camargo’s richness $(1 / S)$} & 0.052 & 0.062 & 0.066 & 0.029 & \\
\hline \multicolumn{2}{|c|}{ Simpson's index of diversity $(1-D)$} & 0.837 & 0.677 & 0.773 & 0.800 & \\
\hline \multicolumn{2}{|c|}{ Shannon index of diversity $(H)$} & 2.349 & 1.746 & 1.739 & 2.068 & \\
\hline
\end{tabular}

${ }^{\mathrm{a}}$ Means isolation frequency estimated for isolated fungal genera

Sixteen out of 90 phenotypes showed activity against at least one chili pepper pathogenic fungi. Eighteen percent of endophytic fungal isolates had antifungal activity against pathogens. Isolates CNU081022 (Penicillium expansum), CNU081032 (Unidentified) and CNU081070 (Unidentified) showed strong antifungal activity against all three tested fungi (Fig. 3). Nine isolates (including strong antagonistic three isolates) were active against all three pathogenic fungi and were identified as Colletotrichum acutatum (CNU081031), Cordyceps nutans (CNU081071) Penicillium sp. (CNU081005, CNU0810023) and Cladosporium sp. (CNU081008 and CNU081044). Eight isolates 
Table 3. Closest relatives of Capsicum annuum L. endophytic fungal isolates based on BLAST search analyses

\begin{tabular}{|c|c|c|c|c|}
\hline Phylum & Isolate no. & Sequence based identification & Similarity \% & Accession number \\
\hline \multicolumn{5}{|c|}{ Ascomycota } \\
\hline & CNU081001, CNU081004 & \multirow[t]{7}{*}{ Penicillium sp. } & \multirow[t]{7}{*}{100} & \multirow[t]{7}{*}{ EU330619 } \\
\hline & CNU081009, CNU081010 & & & \\
\hline & CNU081012, CNU081013 & & & \\
\hline & CNU081014, CNU081015 & & & \\
\hline & CNU081023, CNU081027 & & & \\
\hline & CNU081028, CNU081041 & & & \\
\hline & CNU081082 & & & \\
\hline & CNU081002, CNU081008 & \multirow[t]{3}{*}{ Cladosporium gossypiicola } & \multirow[t]{3}{*}{100} & \multirow[t]{3}{*}{ AF393702 } \\
\hline & CNU081020, CNU081021 & & & \\
\hline & CNU081084 & & & \\
\hline & CNU081005 & Penicillium oxalicum & 100 & AF033438 \\
\hline & CNU081006, CNU081031 & \multirow[t]{4}{*}{ Colletotrichum acutatum } & \multirow[t]{4}{*}{99} & \multirow[t]{4}{*}{ AJ301932 } \\
\hline & CNU081047, CNU081048 & & & \\
\hline & CNU081073, CNU081081 & & & \\
\hline & CNU081088, CNU081089 & & & \\
\hline & CNU081007 & Penicillium citrinum & 99 & DQ681331 \\
\hline & CNU081016, CNU081029 & \multirow[t]{2}{*}{ Alternaria alternata } & \multirow[t]{2}{*}{99} & \multirow[t]{2}{*}{ FJ904919 } \\
\hline & CNU081040, CNU081079 & & & \\
\hline & CNU081017 & Penicillium crustosum & 99 & DQ778917 \\
\hline & CNU081019 & Chaetomium sp. & 99 & AJ279466 \\
\hline & CNU081022 & Penicillium expansum & 100 & FJ008997 \\
\hline & CNU081025 & Aspergillus versicolor & 97 & AJ937751 \\
\hline & CNU081030 & Plectosphaerella cucumerina & 90 & AF132805 \\
\hline & CNU081033 & Geomyces pannorum & 99 & DQ189225 \\
\hline & CNU081034, CNU081086 & Xylaria sp. & 99 & FJ205470 \\
\hline & CNU081035 & Plectosphaerella sp. & 99 & FJ196600 \\
\hline & CNU081038 & Colletotrichum gloeosporioides & 100 & AJ301979 \\
\hline & CNU081043 & Paecilomyces inflatus & 98 & GU566291 \\
\hline & CNU081044 & Cladosporium colombiae & 99 & FJ936159 \\
\hline & CNU081042, CNU081049 & \multirow[t]{3}{*}{ Fusarium oxysporum } & \multirow[t]{3}{*}{99} & \multirow[t]{3}{*}{ AY669119 } \\
\hline & CNU081050, CNU081062 & & & \\
\hline & CNU081063, CNU081064 & & & \\
\hline & CNU081051, CNU081053 & Fusarium solani & 99 & EU029589 \\
\hline & CNU081055 & Bionectria ochroleuca & 99 & EU326186 \\
\hline & CNU081056 & Gnomonia setacea & 99 & AY818958 \\
\hline & CNU081057 & Papulaspora sp. & 99 & DQ132834 \\
\hline & CNU081061 & Penicillium olsonii & 99 & AY373925 \\
\hline & CNU081066 & Aspergillus tubingensis & 99 & GU595290 \\
\hline & CNU081011, CNU081039 & \multirow{4}{*}{ Cladosporium sp. } & \multirow[t]{4}{*}{99} & \multirow[t]{4}{*}{ FJ176478 } \\
\hline & CNU081052, CNU081065 & & & \\
\hline & CNU081067, CNU081072 & & & \\
\hline & CNU081074, CNU081076 & & & \\
\hline & CNU081075 & Cladosporium oxysporum & 99 & AF393720 \\
\hline & CNU081078 & Phialophora cyclaminis & 99 & AB190390 \\
\hline & CNU081083 & Peyronellaea glomerata & 100 & HQ380779 \\
\hline Basidion & ota & & & \\
\hline & CNU081060 & Phanerochaete sordida & 100 & EU047805 \\
\hline & CNU081068 & Phlebiopsis gigantea & 99 & FJ824636 \\
\hline & CNU081069 & Heterobasidion sp. & 99 & FJ627231 \\
\hline & CNU081071 & Cordyceps nutans & 99 & AF224274 \\
\hline & CNU081077 & Irpex lacteus & 100 & EU918701 \\
\hline Unknow & nidentified & & & \\
\hline & $\begin{array}{l}\text { CNU081018, CNU081026, } \\
\text { CNU081058, CNU081059, }\end{array}$ & $\begin{array}{l}\text { 30, CNU081032, CNU081036, Cl } \\
70, \text { CNU081080, CNU081087, Cl }\end{array}$ & , CNU081045 & NU081046, \\
\hline
\end{tabular}




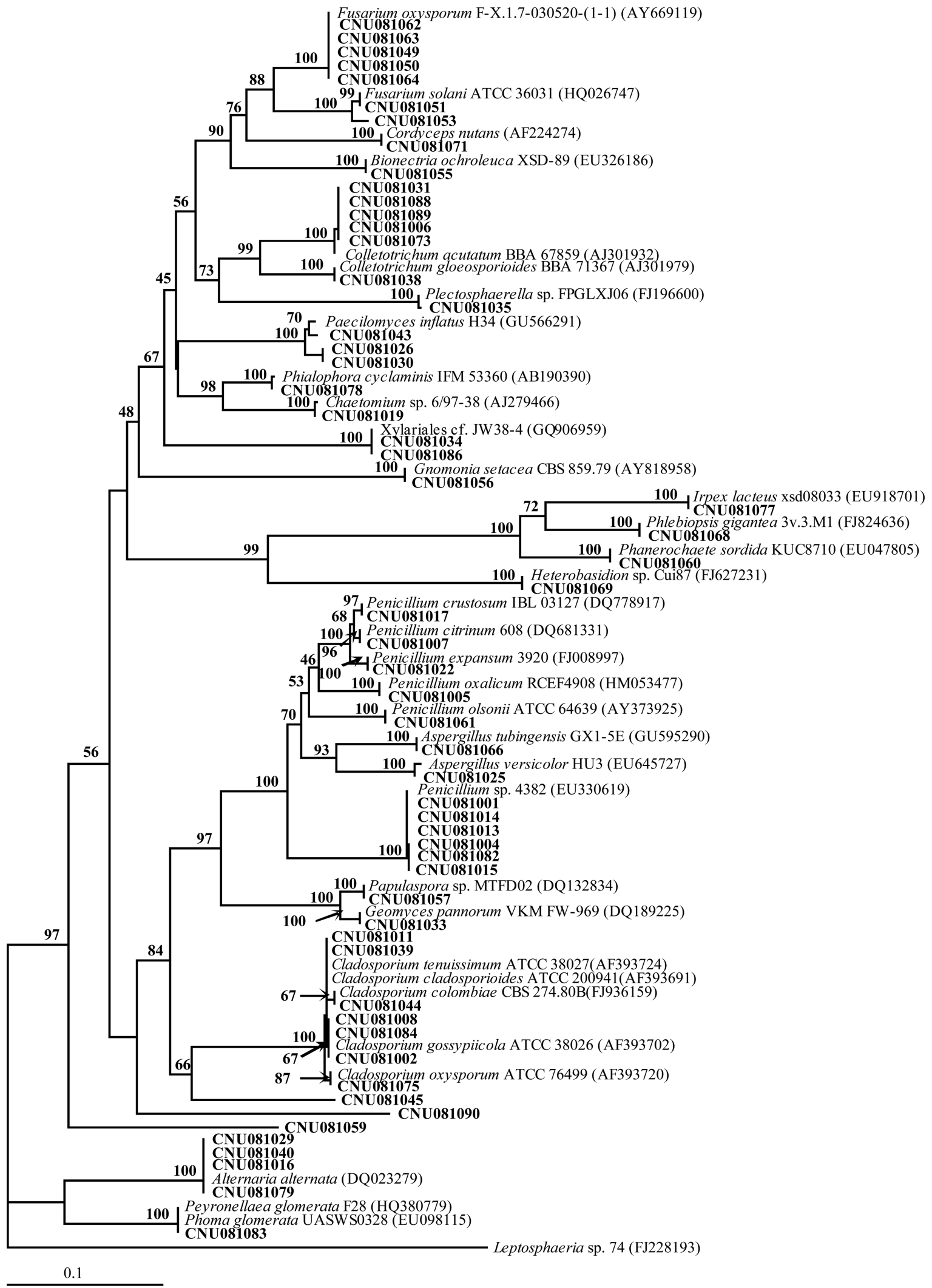

Fig. 2. Neighbor-joining phylogenetic tree showing the placement of the representative endophytic isolates based on the sequences of ITS region. The Kimura two-parameter model is used for pairwise distance measurement. The tree rooted with Leptosphaeria sp. (FJ228193). Only bootstrap values $>50 \%$ (1000 replications) are shown at the branches. 
Table 4. In vitro antifungal activity of endophytic fungi isolated from chili pepper plants against Colletotrichum acutatum, Fusarium oxysporum and Phytophthora capsici

\begin{tabular}{llccc}
\hline \hline \multirow{2}{*}{ Isolate no. } & Endophytic fungi & \multicolumn{4}{c}{ Antagonistic activity } \\
\cline { 3 - 5 } & & Ca & Fo & $P c$ \\
\hline CNU081005 & Penicillium oxalicum & + & + & ++ \\
CNU081006 & Colletotrichum acutatum & - & + & - \\
CNU081007 & Penicillium citrinum & - & + & - \\
CNU081008 & Cladosporium sp. & + & + & + \\
CNU081013 & Penicillium gossypiicola & + & + & - \\
CNU081017 & Penicillium crustosum & + & - & + \\
CNU081021 & Cladosporium gossypiicola & + & - & + \\
CNU081022 & Penicillium expansum & ++ & + & ++ \\
CNU081023 & Penicillium sp. & + & + & + \\
CNU081031 & Colletotrichum acutatum & ++ & + & + \\
CNU081032 & Unidentified & ++ & ++ & ++ \\
CNU081042 & Fusarium oxysporum & + & - & + \\
CNU081044 & Cladosporium colombie & + & ++ & + \\
CNU081070 & Unidentified & ++ & ++ & ++ \\
CNU081071 & Cordyceps nutans & + & + & + \\
CNU081086 & Xylaria sp. & ++ & ++ & - \\
\hline Ca, Colletotrich & &
\end{tabular}

Ca, Colletotrichum acutatum; Fo, Fusarium oxysporum; Pc, Phytophthora capsici; +++ strong activity, ++ moderate activity, + low activity, - no activity

showed moderate activity against all or at least one pathogen and isolates were less potential.

\section{Discussion}

Endophytic microorganisms may increase the plant fitness by improving the tolerance to heavy metals and drought could promote plant growth and reduce the herbivory or phytopathogen settling (Rubini et al., 2005). Endophytic fungal communities associated with various kinds of plants from tropical, sub-tropical, temperate and Arctic ecosystems were investigated previously and found a number of fungi (Rosa et al., 2010). Endophytic fungi reside in other cultivated crop plants also. Margherita et al. (2008) investigated the occurrence of endophytic fungi in fennel, lettuce, chicory and celery which are commercial crops in southern Europe. Larran et al. $(2001,2002)$ isolated endophytic fungi from Argentine tomato and wheat leaves. Cultivated crop plants (tomato, melon, eggplant, cauliflower etc.) were studied in Japan to check their endophytic fungal assemblages (Narisawa et al., 2002). For that reason, we choose the commercial crop Capsicum annuum L. for our experiment.

A number of endophytic fungi consist of sterile mycelia or non sporulating fungi and consequently cannot be identified by morphological method. Previously molecular techniques have been employed successfully for the identification of different endophytic fungal community (Chen et al., 2010, Chen et al., 2011b; Flor et al., 2010; Huang et al., 2008; Roza et al., 2010; Sette et al., 2006). In this study, we also followed the molecular strategy to identify these fungi by means of ITS rDNA gene sequence and phylogenetic analysis.

Endophytic fungal distribution varies with plant-associated habitat which may affect microbial communities that colonize roots, leaves, stems, branches, fruits, pods and leaves (Rubini et al., 2005). Previous investigation revealed that endophytes were isolated from different plant tissues or organs. In this study, we isolated endophytic fungi from leaves, roots and stems of Capsicum annuum L. crop plant but our focus was to check the diversity and distribution of endophytic fungi in seedling, flowering and fruiting stages of chili pepper (Capsicum annuum L.) plant growth. It was a new idea, not previously investigated and we found that Penicillium was the predominant in seedling stage, Fusarium dominated over other fungi in flowering stage where as Colletotrichum and Fusirum were frequently isolated fungi in fruiting stage. Alternaria, Fusarium and Cladosporium were isolated in all growth stages. Isolation frequency was lower in seedling stage. The reason may be the immature growth of root, stem and leaf of chili pepper Even though the Isolation frequency was lower in seedling

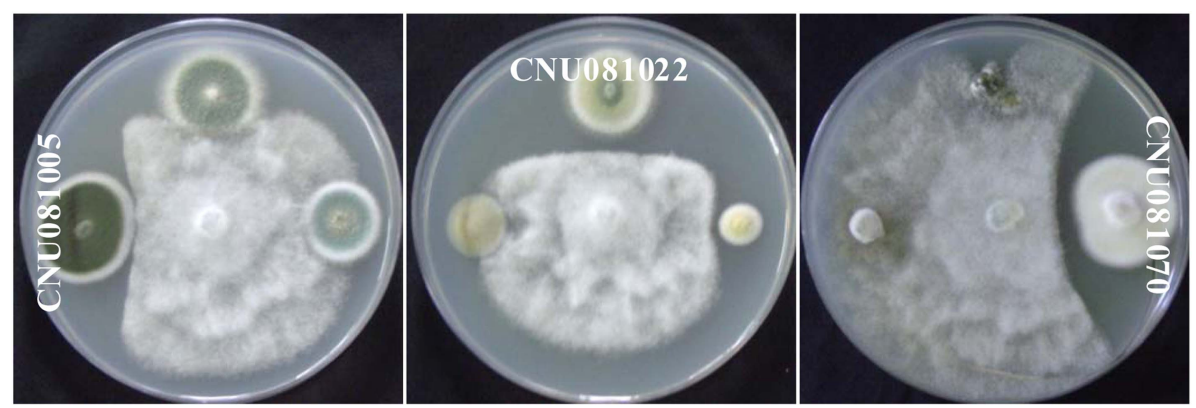

Fig. 3. Endophytic fungi (CNU081005, CNU081022 and CNU081070) from Capsicum annuum L. showing antifungal activity in dual culture antagonistic study against most important chili pepper fungal pathogen Phytophthora capsici. 
stage, species richness (19) was higher than flowering (16) and fruiting stage (15) (Table 2).

In the present study, maximum isolated endophytic fungi belonged to the phylum Ascomycota and few of them were Basidiomycota. Previous report revealed the same common trend. Colletotrichum, Fusarium, Alternaria, Penicillium, Cladosporium, Xylaria were dominated. Similar Ascomycota dominated fungi were reported by Chen et al., 2010a; Chen et al., 2011a; Chen et al., 2011b; Flor et al., 2010; Huang et al., 2008; Huang et al., 2009; Kumar et al., 2010; Lv et al., 2010; Margherita et al., 2008 and Sanchez et al., 2008. Dominated fungi described here as endophytic fungi are commonly associated with disease symptoms in several cultured crop plants. Species of Colletotrichum and Fusarium were most frequently isolated fungi showed the RF value of $18.92 \%$ and $18.71 \%$, respectively. Colletotrichum cause severe disease called anthracnose in many cultivated and non cultivated plants. The anthracnose of chili pepper caused by Colletotrichum acutatum is one of them and at the same time Fusarium oxysporum produce disease in the same plant and many other cultivated and non cultivated plants but both of them were found in association with leaves, roots, pods, and stems as endophytes in many plants. They were found frequently on leaves, stems and roots of Hyperzia serrata in China (Chen et al., 2011b), has been found in association with leaves and stems of medicinal plant Tylophora indica in India (Kumar et al., 2010), found on orchids Dendrobium loddigesii in China (Chen et al., 2010).

Alternaria, Aspergillus, Chaetomium, Cladosporium, Penicillium, Peyronellaea (Phoma) and Xylaria are commonly isolated fungi and also isolated as endophytic fungi. The presence of these genera in our study implies that Capsicum annuи $\mathrm{L}$. plant is the host species of diversified fungi and could play an important role to know the endophytic microbial diversity in crop plants. Rosa et al. (2010); Chen et al. (2011a, 2011b); Yuan et al. (2009); Flor et al. (2010); Huang et al. (2008) and Kumar et al. (2010) also encountered similar Asomycota endophytic fungi from various plant organs. Rare fungal species represented only once or twice in different growth seasons. Basiodiomycota fungi which were rarely isolated and other rare species of Ascomycota were isolated in this experiment also reported by others as endophytic fungi (Benerjee, 2011; Chen et al., 2010; Chen et al., 2011a; Rosa et al., 2010; Sanchez et al., 2008; Sette et al., 2006; Yuan et al., 2009).

Previous results suggesting that these endophytic fungi could play a role in the plant development. Endophytic non pathogenic Phomopsis, Cladosporium, Diaporthe from medicinal plants in Korea promoted the growth (plant biomass growth) of cucumber, tomato and pepper (Paul, 2007). Fusarium oxysporum, a nonpathogenic isolate induced the resistance in cucumber against Pythium ultimum through the combination of antibiosis and mycoparasitism as well as induced plant defense mechanisms (Benhamou et al., 2002). However, in this study we also found that the nonpathogenic endophytic isolates CNU081006 (Colletotrichum acutatum), CNU081042 (Fusarium oxysporum), CNU081005, CNU081007, CNU081017, CNU081022 (Penicillium sp.) inhibited the mycelia growth activity of pathogenic Colletotrichum acutatum and Fusarium oxysporum in dual culture assay (Table 4). Similar results were found by Lv et al., 2010; Wang et al., 2007. They reported that endophytic Fusarium, Cladosporium could inhibit the growth of pathogenic fungi. Our study suggests that endophytes are the source of potential secondary metabolites and biological control agents.

Endophytes are obviously a rich and reliable source of agricultural importance. To the best of our knowledge, this study is the first report of distribution of endophytic fungi in seedling, flowering and fruiting stages of any plant species in the world. Our study suggests that cultivated crops could be the interesting niche that harbors many different fungal species. This study could be the models for further study of endophytic fungal assemblages' in different growth stages of plants.

\section{Acknowledgement}

This study was supported by a grant from 'Regional Subgene bank Support Program' of Rural Development Administration (RDA), Republic of Korea.

\section{References}

Bacon, C. W. 1990. Isolation, culture and maintenance of endophytic fungi of grasses In: Isolation of biotechnological organisms from nature, ed. by D. P. Labeda, McGraw-Hill, New York.

Baltruschat, H., Fodor, J., Harrach, B. D., Niemczyk, E., Barna, B., Gullner, G., Janeczko, A., Kogel, K. H., Schafer, P., Schwarczinger, I., Zuccaro, A. and Skoczowski, A. 2008. Salt tolerance of barley induced by the root endophyte Piriformospora indica is associated with a strong increase in antioxidants. New Phytol. 180:500-510.

Benhamou, N., Garand, C. and Goulet, A. 2002. Ability of nonpathogenic Fusarium oxysporum strain Fo47 to induce resistance against Pythium ultimum infection in cucumber. Appl. Environ. Microbiol. 68:4045-4060.

Benerjee, D. 2011. Endophytic fungal diversity in tropical and subtropical plants. Res. J. Microbiol. 6:54-62.

Bussaban, B., Lumyong, S., McKenzie, E. H. C. and Hyde, K. D. 2001. Endophytic fungi from Ammonium siamense. Can. J. Microbiol. 47:943-948.

Camargo, J. A. 1992. Can dominance influence stability in com- 
petitive interactions?. Oikos. 64:605-609.

Carroll, G. C. 1988. Fungal endophytes in stems and leaves: from latent pathogens to mutualistic symbiont. Ecology 69:2-9.

Chen, X. M., Dong, H. L., Hu, K. X., Sun, Z. R., Chen, J. and Guo, S. X. 2010a. Diversity and antimicrobial and plantgrowth-promoting activities of endophytic fungi in Dendrobium loddigesii Rolfe. J. Plant Growth Regul. 29:328-337.

Chen, J., Hu, K. X. and Hou, X. O. 2011a. Endophytic fungi assemblages from 10 Dendrobium medicinal plants (Orchidaceae). World J. Microbiol. Biotechnol. 27:1009-1016.

Chen, X. Y., Qi, Y. D., Wei, J. H., Zhang, Z., Wang, D. L., Feng, J. D. and Gan, B. C. 2011b. Molecular identification of endophytic fungi from medicinal plant Huperizia serrata based on rDNA ITS analysis. World J. Microbiol. Biotechnol. 27:495-503.

Chun, J. 1995. Computer-assisted classification and identification of actinomycetes. Ph.D. thesis, University of Newcastle, New castle Upon Tyne, UK.

Clay, K. 1989. Clavicipitaceous endophytes of grasses: their potential as biocontrol agents. Mycol. Res. 92:1-12.

Dorworth, C. E. and Callan, B. E. 1996. Manipulation of endophytic fungi to promote their utility as vegetation biocontrol agents. In: Endophytic fungi in grasses and woody plants, ed. by S. C. Reddin and L. M. Carris. APS Press, St. Paul. USA.

Felsenstein, J. 1985. Confidence limits of phylogenies: An approach using the bootstrap. Evolution 39:783-791.

Fisher, P. J. and Petrini, O. 1987. Location of fungal endophytes in tissues of Suaeda fruiticosa: apreliminary study. Trans. Br. Mycol. Soc. 89:246-249.

Fisher, P. J., Andoson, A. E. and Petrini, O. 1986. Fungal endophytes in Ulex europaeus and Ulex gallii. Trans. Br. Mycol. Soc. 86:153-156.

Fisher, P. J., Petrini, O. and Lappin, S. H. M. 1992. The distribution of some fungal and bacterial endophytes in maize (Zea mays L.). New Phytol. 122:299-305.

Flor, N. R., Roberto, A. S., Zolia, N. G. and Luis, B. F. 2010. Diversity of endophytic fungi of Taxus globosa (Mexican yew). Fungal Div. 47:65-74.

Huang, W. Y., Cai, Y. Z., Surveswaran, S., Hyde, K. D., Corke, H. and Sun, M. 2009. Molecular phylogenetic identification of endophytic fungi isolated from three Artemisia species. Fungal Div. 36:69-88.

Huang, W. Y., Cai, Y. Z., Surveswaran, S., Hyde, K. D., Corke, H. and Sun, M. 2008. Biodiversity of endophytic fungi associated with 29traditional Chinese medicinal plants. Fungal Div. 33:61-75.

Kimura, M. 1980. A simple method for estimating evolutionary rate of base substitution through comparative studies of nucleotide sequence. J. Mol. Evol. 16:111-120.

Larran, S., Monaco, C. and Alippi, H. 2001. Endophytic fungi in leaves of Lycopersicon esculentum Mill. World J. Microbiol. Biotechnol. 17:181-184.

Larran, S., Perello, A., Simon, M. R. and Moreno, V. 2002. Isolation and analysis of endophytic microorganisms in wheat (Triticum aestivum L.) leaves. World J. Microbiol. Biotechnol. 18:683-686.
Lv, Y. L., Zhang, F. S., Chen, J., Cui, J. L., Xing, Y. M., Li, X. D. and Guo, S. X. 2010. Diversity and antifungal activity of endophytic fungi associated with the alpine plant Saussurea involucrata. Biol. Pharm. Bull. 33:1300-1306.

Margherita, D., Salvatore, F. and Matteo, C. 2008. Endophytic fungi occurring in fennel, lettuce, chicory and celery-commercial crops in Southern Italy. Mycol. Res. 112:100-107.

Murray, F. R., Latch, G. C. M. and Scott, D. B. 1992. Surrogate transformation of perennial rye grass, Lolium perenne, using genetically modified Acremonium endophyte. Mol. Genet. 233:1-9.

Narisawa, K., Kawamata, H., Currah, R. S. and Hashiba, T. 2002. Supperession of Verticillium wilt in eggplant by some fungal root endophytes. Eur. J. Plant Pathol. 108:103-109.

Park, J. H., Park, J. H., Choi, G. J., Lee, S. W., Jang, K. S., Choi, Y. H., Cho, K. Y. and Kim, J. C. 2003. Screening for antifungal endophytic fungi against six plant pathogenic fungi. Mycobiology 31:179-182.

Park, M. S., Seo, G. S., Bae, K. S. and Yu, S. H. 2005. Characterization of Trichoderma spp. Associated with green mold oyster mushroom by PCR-RFLP and sequence analysis of ITS regions of rDNA. Plant Pathol. J. 21:229-236.

Paul, N. C., Kim, W. K., Woo, S. K., Park, M. S. and Yu, S. H. 2007. Fungal endophytes in roots of Aralia species and their antifungal activity. Plant Pathol. J. 23:287-294.

Paul, N. C. 2007. Diversity of endophytic fungi of medicinal plants in Korea and their antifungal and plant growth promoting activity. Masters thesis, Chungnam National University, Daejeon, Republic of Korea.

Perry, L., Dickau, R., Zarrillo, S., Holst, I., Pearsal, D. M., Piperno, D. R., Berman, M. J., Cooke, R. G., Rademaker, K., Ranere, A. J., Raymond, J. S., Sandweiss, D. H., Scaramelli, F., Tarble, K. and Zeidler, J. A. 2007. Starch fossils and the domestication and dispersal of chili peppers (Capsicum spp. L.) in the Americas. Science (Reports) 315:786-788.

Petrini, O. and Carroll, G. C. 1981. Endophytic fungi in foliage on some Cupressaceae in Oregon. Can. J. Bot. 59:629-636.

Rozin, P. and Schiller, D. 1980. The nature and acquisition of a preference for chili pepper by humans. Motiv. Emotion 4:77101.

Rosa, L. H., Vieira, M. L. A., Santiago, I. F. and Rosa, C. A. 2010. Endophytic fungi community associated with the dicotyledonous plant Colobanthus quitensis (Kunth) Bartl. (Caryophyllaceae) in Antarctica. FEMS Microbiol. Ecol. DOI:10.1111/ j.1574-6941.2010.00872.x.

Rubini, M. R., Silva-Ribeiro, R. T., Pomella, A. W. V., Maki, C. S., Araujo, W. L., Santos, D. R. and Azevedo, J. L. 2005. Diversity of endophytic fungal community of cacao (Theobroma cacao L.) and biological control of Crinipellis perniciosa, causal agent of witches broom disease. Int. J. Biol. Sci. 1:24-33.

Sanchez, M. S., Bills, G. F. and Zabalgogeazcoa, I. 2008. Diversity and structure of the fungal endophytic assemblages from two sympatric coastal grasses. Fungal Div. 33:87-100.

Schardl, C. L., Liu, J., White, J. K., Finkel, R. A., An, Z. and Siegel, M. 1991. Molecular phylogenetic relationship of non- 
pathogenic grass mycosymbionts and clavicipitaceous plant pathogens. Plant Syst. Evol. 178:27-41.

Sette, L. D., Passarini, M. R. Z., Delarmelina, C., Salati, F. and Duarte, M. C. T. 2006. Molecular characterization and antimicrobial activity of endophytic fungi from coffee plants. World J. Microbiol. Biotechnol. 22:1185-1195.

Shannon, C. E. and Weaver, W. 1949. The mathematical theory of communication. University of Illinois Press, Urbana, USA.

Sieber, T., Riesen, T. K., Muller, E. and Fried, P. M. 1988. Endophytic fungi in four winter cultivars (Triticum aestivum L.) differing in resistance against Stagonospora nodorum (Berk.) Cast. And germ.= Septoria nodorum (Berk.) Berk. J. Phytopathol. 122:2289-2306.

Simpson, E. H. 1949. Measurement of species diversity. Nature (London) 163:688.

Spurr, H. W. Jr. and Welty, R. E. 1975. Characterization of endophytic fungi in healthy leaves of Nicotiana spp. Phytopathology $65: 417-422$.

Strobel, G. and Daisy, B. 2003. Bioprocessing for microbial endophytes and their natural products. Microbiol Mol. Biol. Rev. 67:491-502.

Strobel, G. A., Hess, W. M., Ford, E., Sidhu, R. S. and Yang, X. 1996. Taxol from fungal endophytes and the tissue of biodiversity. J. Ind. Microbiol. 17:417-423.

Tanaka, A., Christensen, M. J., Takemoto, D., Park, P. and Scott,
B. 2006. Reactive oxygen species play a role in regulating a fungus-perennial ryegrass mutualistic interaction. Plant Cell 18:1052-1066.

Thompson, J. D., Gibson, T. J., Plewniak, F., Jeanmougin, F. and Higgins, D. G. 1997. ClustalX: windows interface: Flexible strategies for multiple sequence alignment aided by quality analysis tools. Nucleic Acids Res. 25:487-4878.

Tudzynski, B. and Sharon, A. 2002. Biosynthesis, biological role and application of fungal phyto-hormones. In: Osiewacz of Pestalotiopsis isolated as endophytes from medicinal plants. Fungal Div. 24: 37-54.

Yuan, Z. L., Zhang, C. L., Lin, F. C. and Kubicek, P. 2010. Identity, diversity, and molecular phylogeny of the endophytic mycobiota in the roots of rare wild rice (Oryza granulate) from the nature reserve in Yunnan, China. Appl. Environ. Microbiol. March 1642-1652.

Wang, F. W., Jiao, R. H., Cheng, A. B., Tan, S. H. and Song, Y. C. 2007. Antimicrobial potentials of endophytic fungi residing in Quescus variabilis and brefeldin A obtained from Cladosporium sp. World J. Microbiol. Biotechnol. 23:79-83.

White, T. J., Bruns, T. D., Lee, S. B. and Taylor, J. W. 1990. Amplification and direct sequencing of fungal ribosomal DNA for phylogenetics. In: PCR protocols: A guide to the methods and applications, pp. 315. Eds. MA Innes, DH Gelfand JJ, Sninsky and White TJ. Academic Press, New York. 